\title{
Electrochemical Reduction of Tungsten Oxide in LiCl-KCl Molten Salt Eutectic using the Fluidised Cathode Process
}

\author{
Rema Abdulaziz, Leon D. Brown, Douglas Inman, Paul R. Shearing, and Daniel J. L. \\ Brett*
}

Electrochemical Innovation Lab, Department of Chemical Engineering, University College London, Torrington Place, London, WC1E 7JE, United Kingdom

*Email: d.brett@ucl.ac.uk

Tel: +44 (0) 2076793310

Fax: +44 (0) 2073832348

\begin{abstract}
The electrochemical reduction of $\mathrm{WO}_{3}$ to $\mathrm{W}$ metal using a fluidised cathode process has been investigated. Voltammetry was compared with thermodynamic predictions using a predominance diagram for the system to help explain the reaction mechanism. The main reduction potential was located to be $-2.14 \mathrm{~V}$ vs. $\mathrm{Ag} / \mathrm{Ag}^{+}$. By performing near-exhaustive electroreduction at constant potential, the Faradaic current efficiency was estimated to be $>82 \%$. The metal is produced in the form of homogeneous particles bound to the substrate electrode, which can periodically spall off. The effects of metal oxide-to-salt ratio and of fluidisation conditions on the process were investigated. Higher loading of metal oxide particles resulted in an increase in the rate of metallic deposit growth and less current 'noise', while the rate of reduction was relatively insensitive to flow rate of the Ar agitation gas feed, up to a limit where transition to a different flow regime is expected to be the cause of increased reaction rate.
\end{abstract}




\section{Keywords}

Fluidised cathode; molten salt; electrochemical reduction; tungsten oxide; LiCl-KCl eutectic.

\section{Introduction}

The conversion of metals from their ores to their finished refractory stage is both energy and capital intensive. Electrochemical process schemes can significantly reduce operating costs by increasing the energy efficiency of the recovery of metals [1].

For most refractory metals, production via electro-hydrometallurgical routes are not feasible, due to one or more of the following factors [2]: most of these metals can only be electrodeposited at potentials more negative than those required for hydrogen evolution; the metals rapidly become protected by oxide films in oxidizing environments. This can be a problem in fused salt systems too; metallic ions often get transformed to stable oxy-cations in aqueous solutions. The metallic ions of low oxidation states reduce water (e.g. $\mathrm{Ti}^{3+}$ ), and those of high oxidation states oxidise water (e.g. $\left.\mathrm{Ti}^{4+}\right)$.

Due to these factors, the use of molten salts as solvents for electrolytic processes in metal production has emerged as a promising route. Molten salt electrolysis can be used for the electro-winning, refining, plating and forming of refractory metals. The industrial applications of molten salts have been widely acknowledged for more than a century; for example, the commercial production of $\mathrm{Al}, \mathrm{Mg}, \mathrm{Na}, \mathrm{K}, \mathrm{Li}$ and $\mathrm{Be}$ make use of molten salt electrolysis and reduction processes [3].

The intensive research on the subject over the past century has determined the various physical, chemical and thermodynamic properties of molten salt systems to a high standard. Nevertheless, until recently, only a small number of innovative processes of using molten salt 
electrolysis for metal production have been developed [4]. The FFC Cambridge process [5] is one such innovative development in molten salt technology and numerous studies have been carried out to characterise the process and establish its efficiency in reducing metal oxides and producing metal alloys. [6-11]

\subsection{Challenges for electrochemical reduction in molten salts}

There are a number of issues that arise when using electrode rods or porous pellet precursors as electrodes. In the case of titanium oxide reduction via the FFC Cambridge process [5], the current efficiency is quite low $(10-40 \%)$ to achieve sufficiently low oxygen content $(<0.3 \%)$, in the final titanium product [10]. It is desirable to increase the current efficiency and the speed of the process for industrial scale applications [12]. The low efficiency of the process could be due to a number of reasons, including: mass transport limitations, electrolysis of the molten salt, and metal-to-oxide molar volume ratio. Furthermore, the limited diffusion of the electrolyte within the precursor porous matrix is known to leave the inner parts of the materials unreduced $[13,14]$. In the case when using $\mathrm{CaCl}_{2}$, the low current efficiency is usually due to the electronic conduction in the melt due to the solubility of calcium in the electrolyte. When using $\mathrm{LiCl}$ salts, this does not normally apply as lithium does not dissolve in the melt.

In molten salt systems, the point (or line) where the metal phase (current collector or previously reduced metal), the metal oxide phase and the fused salt phase meet is called the three-phase interline (3PI) [15-17]. Along the 3PI, electron transfer occurs between the metal and the metal oxide, and oxide anion transfer occurs between the metal oxide and the molten salt. The 3PI is vital for the electrochemical reduction reaction and a high density of 3PI may increase the overall current density of the system as there are more sites available for the electrochemical reduction to occur. When using a solid-type precursor, as reduction reaction 
proceeds, the 3PI propagates outward from the current collector to the inner parts of the precursor, and then inward from the reduced metallic surface towards the precursor's centre. The current increases initially, plateaus, then reduces until it stops [16]. This is due to the electrolyte not diffusing to the inner parts of the electrode; hence, reducing the 3PI. This is caused by the nature of the morphology of the oxide precursor, and to the change in density and structure of the materials reduced on the surface. For example, some metals tend to have much higher densities than their oxides, resulting in higher porosity of the reduced pellet; however, sometimes this causes the metallic surface to collapse onto itself, creating a much denser morphology, hindering the diffusion of electrolyte.

Precursors in the form of oxide films, pellets or sponge-types are all porous and the size and interconnectivity of these pores affects the reduction process $[10,11]$. When the metal oxide is reduced, some of the oxide ions transfer into the melt and migrate to the anode; however, some of them are trapped in the cathode's pores, as was observed by Dring et al. [18], where it was noted that the concentration of oxide ions at the surface of the electrode was higher than in the bulk molten salt. This can significantly change the potential needed for the reduction. It can also cause the formation of other phases (e.g. calcium titanate) due to the salt cation reacting with the oxygen ions on the surface. Moreover, Brown et al. [19] showed significant changes in the tortuosity of the cathode microstructure during electrochemical reduction of $\mathrm{UO}_{2}$ to $\mathrm{U}$ in molten $\mathrm{LiCl}-\mathrm{KCl}$ eutectic which could also impede the transport of oxygen anions.

Thus, new process designs are desirable to improve the efficiency and performance of the electrochemical reduction of metal oxides. A promising route is the 'fluidised cathode' process [20]. 


\subsection{Fluidised bed electrochemical processes}

Numerous experimental, theoretical and review studies have been published on fluidised bed electrochemical processes. The main advantages of employing fluidised bed electrodes are their large specific area (high specific productivity) [21]. Applications include fuel cells, hydrogen peroxide synthesis [22, 23], water purification and organic electrosynthesis [24, 25].

Fluidised bed electrodes have been studied and used industrially in various applications, though their definition is not certain; for example, sometimes they are reducing agents and other times they act as catalysts, yet they are still loosely termed 'fluidised bed electrodes'. Until recently, they have not been applied in molten salt electrochemical reduction processes [20]; however, they may be a viable route to increasing the performance of such processes. In the proposed arrangement, metal oxide particles are suspended in the molten salt, via the use of an agitator (e.g. inert gas bubbling or stirring). An inert electrode is held at a suitable potential and the anode separated in its own compartment, to stop the reoxidation of the reduced metal particles. Fig. 1 shows a schematic of the fluidised cathode process, and the different paths that a metal oxide particle could follow. Spalling off of the reduced metal particles from the current collector has been observed experimentally [20].

Numerous studies on the electrochemical reduction of metal oxide particles on surfaces have recently been published [26-28]; however, these particles were small in size, not fluidised, and were used for thin film preparation. The fluidised cathode process is a larger scale threephase metal oxide-to-metal reduction process. 3PI is continuously being created, every time an impinging metal oxide particle comes into contact with the current collector. The matrix of the fluidised cathode also promotes the diffusion of electrolyte within the metal oxide particles, and of the oxygen ions within the electrolyte. Another proposed advantage of using a fluidised cathode process is that it would eliminate certain steps in the preparation of the 
precursor and recovery of the reduced metal in the FFC Cambridge process [29], with associated cost reductions.

Tungsten has many applications because of its physical and chemical properties [30]. Tungsten ore is usually extracted then converted to $\mathrm{WO}_{3}$, which is in turn reduced to $\mathrm{W}$ metal by hydrogen and heating. This process is time and energy intensive [31]. The electrochemical reduction route might prove to be viable for the production of pure tungsten. Studies on the electrochemical reduction of tungsten oxide in molten salts have been published [32-34], mainly for the production of metal alloys $[8,35]$ wherein the precursors were porous solids in the form of pellets.

This article reports an investigation of different factors that affect the fluidised cathode process and the current efficiency that can be achieved, using a model system of tungsten oxide and $\mathrm{LiCl}-\mathrm{KCl}$ molten salt eutectic.

\section{Experimental}

\subsection{Apparatus}

Figure 2 is a schematic of the electrolytic cell used. The relatively low melting point of LiCl$\mathrm{KCl}$ eutectic $\left(352^{\circ} \mathrm{C}\right)$ allows the use of borosilicate glass which provides optical access to the fluidised cathode compartment. A thermostatic salt bath $\left(\mathrm{NaNO}_{3}-\mathrm{KNO}_{3}\right)$, also contained in borosilicate glass, heated via an immersion heater [36], is used to heat the electrolytic cell to the desired temperature. The cathode consists of $\mathrm{WO}_{3}$ particles that are suspended in the molten salt $(\mathrm{LiCl}-\mathrm{KCl})$ eutectic, which is placed inside a tall form beaker of $250 \mathrm{~mL}$ volume (60 $\mathrm{mm}$ in diameter and $120 \mathrm{~mm}$ height to account for the changing height of the electrolyte due to agitation), and a pure tungsten rod current collector. The anode is a graphite rod separated in its own compartment to avoid reoxidation of the reduced tungsten particles; the anode compartment has an opening at the top (inside the sealed cell) to allow for gas to 
escape. The melt is agitated via a flow of argon. A reference electrode $\left(\mathrm{Ag} / \mathrm{Ag}^{+}\right)$[37] was used, and the temperature was monitored via a glass sheathed thermocouple that is immersed in the melt. All electrochemical tests were performed using a potentiostat (IviumStat, Ivium Technologies, NL).

A similar set-up was used to carry out the thin film studies. In this setup, no $\mathrm{WO}_{3}$ particles were employed, the counter electrode was not separated inside a compartment, no argon was bubbled through the melt, and the current collector was replaced with a thin film cathode.

\subsection{Chemicals}

All preparation steps were carried out under a sealed argon atmosphere. Anhydrous lithium chloride (ACS reagent, $\geq 99.0 \%$ purity, Sigma-Aldrich) and potassium chloride $(\geq 99.5 \%$ purity, Sigma-Aldrich) were used for the electrolyte. The salt was dried in a vacuum oven at $200{ }^{\circ} \mathrm{C}$ for $24 \mathrm{~h}$, then $150 \mathrm{~g}$ of $59-41 \mathrm{~mol} \% \mathrm{LiCl}-\mathrm{KCl}$ were mixed with $\mathrm{WO}_{3}(99.9 \%$ purity, Alfa Aesar). Particle size distribution measurements were conducted using a Beckman Coulter LS13320 laser diffraction particle size analyser; they showed a mean particle diameter of $30.92 \mu \mathrm{m}$ (refer to supplemental material - S1). The X-ray diffraction pattern of the as-received $\mathrm{WO}_{3}$ powder also showed pure $\mathrm{WO}_{3}$ (refer to supplemental material $-\mathrm{S} 2$ ). 15 $\mathrm{g}$ of LiCl-KCl was placed inside the anode compartment. The counter electrode was a high density graphite rod, $3.05 \mathrm{~mm}$ in diameter (99.9995\% metal basis, Alfa Aesar). The working electrode (current collector) was a tungsten rod, $1.5 \mathrm{~mm}$ in diameter $(99.95 \%$ metal basis, Alfa Aesar). A glass sheath around the shaft of the tungsten rod insured that a constant electrode surface area is exposed to the electrolyte, even when being agitated by the $\mathrm{Ar}$ stream. Argon (99.998\% purity, BOC) was bubbled through the melt via a ceramic tube (5 $\mathrm{mm}$ internal diameter, Alsint). 
For the thin film experiments, the electrolyte was composed of $150 \mathrm{~g}$ of $\mathrm{LiCl}-\mathrm{KCl}$, prepared in the same way as for the fluidised cathode setup, but no $\mathrm{WO}_{3}$ particles were used. The working electrode was thermally oxidised in air at a temperature ramp rate of $250{ }^{\circ} \mathrm{C} \mathrm{h}^{-1}$, then held at $700{ }^{\circ} \mathrm{C}$ for $2 \mathrm{~h}$.

\subsection{Procedure}

Experiments were carried out under a dry argon atmosphere at a melt temperature of $450{ }^{\circ} \mathrm{C}$. Argon was bubbled into the melt (the flow rate for this is indicated in the results section for each experiment), which resulted in a homogeneous distribution of particles as assessed by visual inspection. The current collector was immersed to $4 \mathrm{~cm}\left(3.84 \mathrm{~cm}^{2}\right)$ in the melt during the fluidised cathode measurements, and $2 \mathrm{~cm}\left(1.96 \mathrm{~cm}^{2}\right)$ during the thin film measurements. However, absolute currents are reported due to the fact that the electrode surface area changes during experiments.

\section{Results and discussion}

A predominance diagram [38-40] was constructed for the $\mathrm{Li}-\mathrm{K}-\mathrm{W}-\mathrm{O}-\mathrm{Cl}$ system, relating the potential $E$ vs. standard chlorine electrode (S.Cl.E) to the negative logarithm of $\mathrm{O}^{2-}$ ion activity, $p \mathrm{O}^{2-}$. The thermodynamic data used for the production of the diagram is presented in

Table 1. A predominance diagram for tungsten species in $\mathrm{CaCl}_{2}$ has been published [8]; however, this is the first reported of the LiCl- $\mathrm{KCl}$ eutectic. From Dring et al. [35], $\mathrm{WCl}_{2} \mathrm{O}_{2}$ was the only oxychloride state accounted for, as it is the only one stable in molten salts, this is perhaps due to the fact that the bands of stability of the other oxychloride species are too small for them to exist, or show on the diagram.

The predominance diagram in Fig. 3 shows the different regions of stability for different compounds and oxidation states of tungsten. From a thermodynamic perspective, the 
predominance diagram shows that there is a wide window of $\mathrm{O}^{2-}$ ion activity through which the oxide can be reduced to pure metal without interference from electrolyte cation reduction or the formation of oxychlorides or lithium complexes. Starting with $\mathrm{WO}_{3}$, two reduction reactions take place to produce $\mathrm{W}$ metal. These are presented in Equations 1 and 2. Equations 3 and 4 are used to calculate the potential, $E$, needed for each reaction to take place, at different values of $\mathrm{O}^{2-}$ ion activity.

$$
\begin{aligned}
& W O_{3}+2 e^{-} \leftrightarrow W O_{2}+O^{2-} \\
& W O_{2}+4 e^{-} \leftrightarrow W+2 O^{2-} \\
& E_{1}=\frac{-\Delta G_{1}^{0}}{2 F}+\frac{R T \ln 10}{2 F} p O^{2-} \\
& E_{2}=\frac{-\Delta G_{2}^{0}}{4 F}+\frac{2 R T \ln 10}{4 F} p O^{2-}
\end{aligned}
$$

Voltammetry measurements were performed on a thermally grown thin film of $\mathrm{WO}_{3}$ and a fluidised cathode of $\mathrm{WO}_{3}$ particles, Fig. 4 (a) and (b) respectively. Both were scanned from 0 $\mathrm{V}$ to $-2.7 \mathrm{~V}$, and back to $0 \mathrm{~V}$ (vs. $\mathrm{Ag} / \mathrm{Ag}^{+}$reference electrode). The peaks at 2 represent the evolution of $\mathrm{Li}$, and at 3 represent its reionisation. The peaks at 1 represent the main reduction steps as described by the overall reaction in Equation 5 (where the $\mathrm{O}^{2-}$ ions react with the carbon anode after some time). The smaller peaks appearing after 3 in the positive direction represent the reoxidation of $\mathrm{W}$ to $\mathrm{WO}_{\mathrm{x}}$

$W O_{3}+6 e^{-} \leftrightarrow W+3 O^{2-}$ 5

When comparing the reduction peaks for the two systems in Fig. 4 (a) and (b), one can see that the peak in (b) is slightly more positive, and appears at $-2.14 \mathrm{~V}$, compared to $-2.21 \mathrm{~V}$ in (a), as indicated by the dashed vertical lines in the diagrams. In the fluidised cathode, a 3PI is instantly initiated at the collision point of a particle with the current collector in the fluidised cathode process, thus the reaction extends from this point. In the case of a thin film, there is 
an insulating sheath of oxide covering the electrode surface, and therefore it is harder for the reaction to initiate, resulting in a greater required driving force (more negative potential).

Closer examination of the voltammetry of the fluidised cathode system, Fig. 5, shows the apparent 'noise' in the voltammetry due to particle/current collector reactions. One can see that the collision-reaction features are only evident at voltages where $\mathrm{WO}_{3}$ can be reduced; the anodic peaks do not display this feature, indicating that the re-oxidation of the current collector to $\mathrm{WO}_{\mathrm{x}}$ is primarily a surface process involving $\mathrm{W}$ on the surface and not as a result of reduced $\mathrm{W}$ particles colliding and reacting with the electrode. One can see that the electrochemical reaction proceeds from $-1.13 \mathrm{~V}$, the noise in the diagram is also indicative of this. When comparing the voltages involved with the thermodynamically calculated ones and the predominance diagram, it suggests that the process starts with an electrochemical reaction, Equation 1, which produces $\mathrm{WO}_{2}$. This then proceeds to reduce electrochemically to W metal in a 4-electron-transfer step, Equation 2.

Ideally, an electrochemical reduction process would progress vertically down the predominance diagram; however, in reality this is complicated by the formation of $\mathrm{O}^{2-}$ which causes the local conditions at the electrode to move to the 'left' as the reduction proceeds. Previous studies where solid precursors have been removed from the melt mid-reduction and analysed support this $[7,8,41]$. In the case of tungsten reduction, the reduction seems to occur directly from $\mathrm{WO}_{3}$ to $\mathrm{WO}_{2}$ to $\mathrm{W}$ metal; unlike titanium reduction, where the perovskite $\mathrm{CaTiO}_{3}$ is formed in small quantities.

In the XRD analyses, referred to in Section 3.1, the intermediate step $\mathrm{WO}_{2}$ never showed up in the readings. This is due to the fact that its stability range is very narrow, as predicted by the predominance diagram, however the cyclic voltammograms suggest a 2 -step mechanism, and that is because when the potential is continuously is continuously changing the $\mathrm{O}^{2-}$ ion activity also does, enabling the $\mathrm{WO}_{2}$ phase to exist for longer and be captured on the cyclic 
voltammogram readings. Other literature also suggests that this is the most common reduction mechanism [35], some even suggest other intermediate steps, such as $\mathrm{WO}_{2.72}$ and $\mathrm{WO}_{2.90}$ [42]; however, given the rapid reactions and the time scale, and the fact that no intermediate phases were observed in the analyses, the 2-step mechanism was the most convincing.

Figure 6 shows the chronoamperogram for the fluidised cathode reduction of $\mathrm{WO}_{3}$ when the electrode was held at a constant potential of $-2.14 \mathrm{~V}$ (vs. $\mathrm{Ag} / \mathrm{Ag}^{+}$reference electrode). In previous studies $[6,9,11,35]$ potentials in the range of $2-3 \mathrm{~V}$ have been applied for such metal oxide reduction processes. As time passed, the current increased due to an increase in the electrode surface area and the deposit growth of $\mathrm{W}$ on the current collector surface. Fig. 8 (b) shows an image of the current collector before and after the reduction, and (c) shows an image of the solidified melt after the reduction, showing separate layers of $\mathrm{WO}_{3}$ and $\mathrm{W}$ at the bottom of the reactor's crucible. SEM (Carl Zeiss XB1540, accelerating voltage: $20.00 \mathrm{kV}$ ) analyses showed that there was no detectable oxygen present in the final $\mathrm{W}$ product. A crosssection of the retrieved current collector, where the deposit did not spall off, shows that the growth is radial in shape, Fig. 7, i.e. it forms at the same rate perpendicular to the current collector surface in all radial directions. At higher magnification, Fig. 8, the particles of W metal produced appear homogeneous in size and porosity, the sintered reduced particles having a feature size of $\sim 5-10 \mu \mathrm{m}$, compared to the free oxide particles which had a mean particle diameter of $\sim 31 \mu \mathrm{m}$.

\subsection{Current efficiency}

A constant potential of $-2.14 \mathrm{~V}\left(\mathrm{vs} . \mathrm{Ag} / \mathrm{Ag}^{+}\right.$) was applied to the fluidised cathode set-up to reduce $4 \mathrm{~g}$ of $\mathrm{WO}_{3}$ to $\mathrm{W}$ metal, Fig. 9. The chronoamperogram shows a similar trend to previously published work on electrochemical reduction of metal oxides [7], where the 
process can be segregated into two main sections; the first, where rapid reduction reactions occur and the current increases as the electrode grows in size; the current then decreases, with periodic spalling events resulting in rapid current decrease, this is associated with decrease in available oxide which continues to diminish down to the background current level as the reactant is completely exhausted.

Assuming 100\% current efficiency, it would require a charge of $9977 \mathrm{C}$ to be applied to fully reduce all $4 \mathrm{~g}$ of $\mathrm{WO}_{3}$. The XRD spectrum of the product (refer to supplemental material S3), retrieved from the deposit on the current collector shows that it is composed of metallic $\mathrm{W}$ and $\mathrm{KCl}$ and shows no signs of $\mathrm{WO}_{3}, \mathrm{WO}_{2}$ or any other quasi-reduced species. Thus, it confirms that the reduction reaction can reach completion with pure $\mathrm{W}$ being the product. The precise determination of the Faradaic efficiency for such a batch system is challenging as it involves the process going to completion (which takes a long time) and accounting for background currents caused by oxygen ingress into the apparatus (estimated from preelectrolysis to be $4.3 \mathrm{~mA}$ ). Faradaic efficiency was calculated by dividing the theoretical charge required by the charge passed for a known amount of $\mathrm{WO}_{3}$. To account for background current and the process not going to absolute completion, a Faradaic efficiency 'range' can be determined by linearly extrapolating the current to either zero or considering the background current to be the limit of reaction. In which case a Faradaic efficiency between $82 \%$ and $100 \%$ results.

When the final product was retrieved, a sample was placed in ethanol to dissolve the salt, under an argon atmosphere. Dissolving the salt in water was not appropriate in this case, as $\mathrm{W}$, unlike Ti, reacts more readily with water (and air) forming thin films of oxides, which was not desired for analysis. After leaving the sample in ethanol for $24 \mathrm{hr}$, the ethanol containing salt was removed by vacuum filtration. The sample (powder) was then placed in ethanol again, and the procedure was repeated twice. Finally, the product was dried in a 
vacuum oven at room temperature. Despite this rigorous cleaning process, the XRD spectrum (refer to supplemental material - S3) confirms that $\mathrm{KCl}$ is still present in the sample. A possible solution to this could be by employing vacuum distillation $[43,44]$ at high temperature to remove the salt whilst still molten.

\subsection{Effects of metal oxide-to-salt ratio}

Constant potential experiments were carried out on different loadings of $\mathrm{WO}_{3}$ powder in $\mathrm{LiCl}-\mathrm{KCl}$ salt eutectic. The voltage was again set to $-2.14 \mathrm{~V}$, Fig. 10. Three chronoamperometry measurements were taken. Masses of $\mathrm{WO}_{3}(0.5,40$ and $60 \mathrm{~g})$ were initially mixed with $150 \mathrm{~g}$ of $\mathrm{LiCl}-\mathrm{KCl}$ in the main cell crucible, with $10 \mathrm{~g}$ in the anode compartment, giving weight percentages of $0.312,20.00$ and $27.27 \mathrm{wt} \%$, for the three different experiments. $0.5 \mathrm{~g}$ was chosen, as this was the lowest limit at which some product could still be retrieved from the current collector. $60 \mathrm{~g}$ was chosen, as this was the highest limit, given the ratio to $150 \mathrm{~g}$ of salt, where the fluidisation process was still easily initiated. Although masses of up to $100 \mathrm{~g}$ of $\mathrm{WO}_{3}$ could still be fluidised, they proved difficult to initiate and maintain a stable fluidised system using the gas bubbling method.

The chronoamperograms in Fig. 10 all show an initial increase in current with time. They all stabilise towards different currents, with the lowest weight percentage achieving a lower current than the higher weight percentage experiments. Spalling-off is also witnessed, with associated sudden drops in currents passed. The effect of metal oxide concentration in the melt on the current passed is attributed to the fact that statistically there are more frequent interactions of particles with the electrode for a system with higher loading, thus giving a higher total current. The difference in change in current with time is more intriguing. The high metal oxide concentration leads to a monotonic increase in current with time, while the lower concentrations show more signs of product spalling, evident through the abrupt 
decrease in current. This would suggest that the product is more stable in the high concentration case, allowing growth to continue and the electrode to grow.

Figure 11 shows the count of charge per current spike $\left(\mathrm{C}\right.$ spike $\left.{ }^{-1}\right)$ relative to a normalised line of best fit for the chronoamperograms in Fig. 10. 2500 points for each $\mathrm{WO}_{3}$ concentration were used to produce the data. It is clear that with higher concentrations the noise is much smaller. The increasing noise with the decreasing oxide particle fraction is also attributed to the greater particle homogeneity in the melt leading to a steadier current response. A higher, more constant level of particle / electrode interaction will tend to even out the response.

\subsection{Effects of fluidisation rate}

Different argon flow rates were applied to the fluidised cathode process whilst conducting a constant voltage experiment. Fig. 12 shows the chronoamperogram of the fluidised cathode under different agitation conditions. The reduction potential was set to $-2.14 \mathrm{~V}$ and the fluidisation rate was altered by changing the argon flow rates from $200 \mathrm{~cm}^{3} \mathrm{~min}^{-1}$ to a maximum of $1800 \mathrm{~cm}^{3} \mathrm{~min}^{-1}$, and back to $200 \mathrm{~cm}^{3} \mathrm{~min}^{-1}$. It was increased by $200 \mathrm{~cm}^{3} \mathrm{~min}^{-1}$ every 5 minutes. As time passed, at each argon flow rate the current increased; again this is due to an increase in the surface area of the current collector. Above $200 \mathrm{~cm}^{3} \mathrm{~min}^{-1}$ and up to $1600 \mathrm{~cm}^{3} \mathrm{~min}^{-1}$ the increase in current was quite insensitive to the argon flow rate but made the current-noise increase. This implies that the number of collisions and rate of electroreduction was not sensitive to the fluidisation rate. Above $1600 \mathrm{~cm}^{3} \mathrm{~min}^{-1}$ there is a step change increase in the current. In fluidised bed engineering, there are two main types of fluidisation regimes, depending on many parameters, but mainly the superficial velocity of the fluid, the fluidisation regime can change from a 'particulate' to an 'aggregative' regime. This sudden increase in current may be a consequence of such a change in the fluidisation regime specific to this three-phase system. 
Figure 13 shows the count of charge per spike relative to a normalised line of best fit for the chronoamperogram in Fig. 12. Three hundred points for each argon flow rate were used to plot the data. Here, one can clearly see that increasing flow rate results in increasing current noise. Given that below $1600 \mathrm{~cm}^{3} \mathrm{~min}^{-1}$ reaction rate is not significantly affected by the flow rate, it is possible that the increased current noise is caused by the bubbles interfering with the electrode process and intermittently blocking the electrode surface.

\section{Conclusions}

The electrochemical reduction of $\mathrm{WO}_{3}$ to $\mathrm{W}$ metal has been assessed, and is likely to occur following the reactions $\mathrm{WO}_{3} \rightarrow \mathrm{WO}_{2} \rightarrow \mathrm{W}$, Equations 1 and 2. A near full reduction using the fluidised cathode process, with conversion of the product to $\mathrm{W}$ was carried out, via applying a constant potential of $-2.14 \mathrm{~V}$. The Faradaic current efficiency was found to be $82-100 \%$. The reduction process is split into two sections; the first where rapid reduction of the majority of the $\mathrm{WO}_{3}$ occurs, the second where the remaining oxides are slowly removed to completion. The deposited material on the current collector is in the form of homogeneously distributed particles; however, spalling off of the product occurs intermittently.

Increasing the metal oxide-to-salt ratio results in increasing current (faster deposit growth on the current collector), and decreasing collision-reaction noise, and has less likelihood of product to spall off. The melt matrix is well fluidised above $200 \mathrm{~cm}^{3} \mathrm{~min}^{-1}$ and relatively insensitive to fluidisation rate up to $1600 \mathrm{~cm}^{3} \mathrm{~min}^{-1}$, above which a transition to a more effective fluidisation regime may be the cause of increased current.

The fluidised cathode is a robust, three-dimensional, high efficiency process. It has been studied here for the electrochemical reduction of tungsten oxide; however, it is likely 
applicable for other refractory metals (such as titanium), and in the nuclear industry for pyroprocessing purposes of spent nuclear materials.

\section{Acknowledgements}

This work was carried out as part of the UK Engineering and Physical Sciences Research Council (EPSRC) funded REFINE consortium (http://www.refine.eng.ed.ac.uk/) (EP/J000531/1) and EPSRC PACIFIC programme (EP/L018616/1). Shearing acknowledges financial support from the Royal Academy of Engineering.

\section{References}

[1] D.R. Sadoway, New opportunities for metals extraction and waste treatment by electrochemical processing in molten salts, J. Mater. Res., 10 (1995) 487.

[2] D. Inman, S.H. White, The production of refractory metals by the electrolysis of molten salts; design factors and limitations, J. Appl. Electrochem., 8 (1978) 375.

[3] B. Mishra, D.L. Olson, Molten salt applications in materials processing, J. Phys. Chem. Solids, 66 (2005) 396.

[4] D.J. Fray, Emerging molten salt technologies for metals production, JOM, 53 (2001) 27.

[5] G.Z. Chen, D.J. Fray, T.W. Farthing, Direct electrochemical reduction of titanium dioxide to titanium in molten calcium chloride, Nature, 407 (2000) 361. 
[6] R. Bhagat, D. Dye, S.L. Raghunathan, R.J. Talling, D. Inman, B.K. Jackson, K.K. Rao, R.J. Dashwood, In situ synchrotron diffraction of the electrochemical reduction pathway of TiO2, Acta Mater., 58 (2010) 5057.

[7] R. Bhagat, M. Jackson, D. Inman, R. Dashwood, The Production of Ti-Mo Alloys from Mixed Oxide Precursors via the FFC Cambridge Process, J. Electrochem. Soc., 155 (2008) E63.

[8] R. Bhagat, M. Jackson, D. Inman, R. Dashwood, Production of Ti-W Alloys from Mixed Oxide Precursors via the FFC Cambridge Process, J. Electrochem. Soc., 156 (2009) E1.

[9] C. Schwandt, D.J. Fray, Determination of the kinetic pathway in the electrochemical reduction of titanium dioxide in molten calcium chloride, Electrochim. Acta, 51 (2005) 66.

[10] C. Schwandt, D.T.L. Alexander, D.J. Fray, The electro-deoxidation of porous titanium dioxide precursors in molten calcium chloride under cathodic potential control, Electrochim. Acta, 54 (2009) 3819.

[11] D.T.L. Alexander, C. Schwandt, D.J. Fray, The electro-deoxidation of dense titanium dioxide precursors in molten calcium chloride giving a new reaction pathway, Electrochim. Acta, 56 (2011) 3286. 
[12] K. Jiang, X. Hu, M. Ma, D. Wang, G. Qiu, X. Jin, G.Z. Chen, “Perovskitization”Assisted Electrochemical Reduction of Solid $\mathrm{TiO}_{2}$ in Molten $\mathrm{CaCl}_{2}$, Angew. Chem. Int. Ed., 45 (2005) 428.

[13] G. Garcia Belmonte, V. Garciabelmonte, J. Vikhrenko, J. Garciacanadas, Bisquert, Interpretation of variations of jump diffusion coefficient of lithium intercalated into amorphous $\mathrm{WO}_{3}$ electrochromic films, Solid State Ion., 170 (2004) 123.

[14] G. Garcia-Belmonte, J. Garcia Belmonte, Bisquert, Impedance analysis of galvanostatically synthesized polypyrrole films. Correlation of ionic diffusion and capacitance parameters with the electrode morphology, Electrochim. Acta, 47 (2002) 4263.

[15] Y. Deng, Wang, W. Xiao, Jin, Hu, G.Z. Chen, Electrochemistry at Conductor/Insulator/Electrolyte Three-Phase Interlines: A Thin Layer Model, J. Phys. Chem. B, 109 (2005) 14043.

[16] G. Chen, E. Gordo, D. Fray, Direct electrolytic preparation of chromium powder, Metall. Mater. Trans. B, 35 (2004) 223.

[17] P. Kar, J.W. Evans, A model for the electrochemical reduction of metal oxides in molten salt electrolytes, Electrochim. Acta, 54 (2008) 835.

[18] K. Dring, R. Dashwood, D. Inman Voltammetry of Titanium Dioxide in Molten Calcium Chloride at $900^{\circ} \mathrm{C}$, J. Electrochem. Soc., 152 (2005) E104. 
[19] L.D. Brown, R. Abdulaziz, B. Tjaden, D. Inman, D.J.L. Brett, P.R. Shearing, Investigating microstructural evolution during the electroreduction of $\mathrm{UO}_{2}$ to $\mathrm{U}$ in $\mathrm{LiCl}-\mathrm{KCl}$ eutectic using focused ion beam tomography, J. Nucl. Mater., (2016).

[20] R. Abdulaziz, L.D. Brown, D. Inman, S. Simons, P.R. Shearing, D.J.L. Brett, Novel fluidised cathode approach for the electrochemical reduction of tungsten oxide in molten LiCl-KCl eutectic, Electrochem. Commun., 41 (2014) 44.

[21] F. Coeuret, The fluidized bed electrode for the continuous recovery of metals, J. Appl. Electrochem., 10 (1980) 687.

[22] C. Oloman, A.P. Watkinson, Hydrogen peroxide production in trickle-bed electrochemical reactors, J. Appl. Electrochem., 9 (1979) 117.

[23] Y. Xiong, H.T. Karlsson, An experimental investigation of chemical oxygen demand removal from the wastewater containing oxalic acid using three-phase three-dimensional electrode reactor, Adv. Environ. Res., 7 (2002) 139.

[24] F. Goodridge, C.J.H. King, A.R. Wright, Performance studies on a bipolar fluidised bed electrode, Electrochim. Acta, 22 (1977) 1087.

[25] S. Germain, F. Goodridge, Copper deposition in a fluidised bed cell, Electrochim. Acta, $21(1976) 545$. 
[26] W. Xiao, X. Xiao, H. Wang, H. Yin, X. Zhu, D. Mao, Wang, Verification and implications of the dissolution-electrodeposition process during the electro-reduction of solid silica in molten $\mathrm{CaCl}_{2}$, RSC Adv., 2 (2012) 7588.

[27] W. Xiao, X. Xiao, G. Jin, Chen, Up-scalable and controllable electrolytic production of photo-responsive nanostructured silicon, J. Mater. Chem. A, 1 (2013) 10243.

[28] A. Boika, S.N. Thorgaard, A.J. Bard, Monitoring the Electrophoretic Migration and Adsorption of Single Insulating Nanoparticles at Ultramicroelectrodes, J Phys. Chem. B, 117 (2012) 4371.

[29] K.S. Mohandas, D.J. Fray, FFC Cambridge process and removal of oxygen from metaloxygen systems by molten salt electrolysis: an overview, T. Indian I. Metals, 57 (2004) 579.

[30] E. Lassner, W.-D. Schubert, Tungsten: properties, chemistry, technology of the element, alloys, and chemical compounds, Springer Science \& Business Media, 2012.

[31] E. Lassner, From Tungsten Concentrates and Scrap to Highly Pure Ammonium Paratungstate (APT), The Chemistry of Non-Sag Tungsten, Pergamon, Oxford, 1995, 35-44.

[32] V. Malyshev, A. Gab, A.-M. Popescu, V. Constantin, Electroreduction of tungsten oxide(VI) in molten salts with added metaphosphate, Chem. Res. Chin. Univ., 29 (2013) 771.

[33] X. Xi, G. Si, Z. Nie, L. Ma, Electrochemical behavior of tungsten ions from WC scrap dissolution in a chloride melt, Electrochim. Acta, 184 (2015) 233. 
[34] G. Si, X. Xi, Z. Nie, L. Zhang, L. Ma, Preparation and characterization of tungsten nanopowders from WC scrap in molten salts, Int. J. Refract. Met. H., 54 (2016) 422.

[35] K. Dring, R. Dring, M. Bhagat, R. Jackson, D. Dashwood, Inman, Direct electrochemical production of Ti-10W alloys from mixed oxide preform precursors, J. Alloys Compd., 419 (2006) 103.

[36] D. Inman, J.O.M. Bockris, The application of the galvanostatic potential - time technique to analysis in molten salts, J. Electroanal. Chem., 3 (1962) 126.

[37] J.O.M. Bockris, G.J. Bockris, D. Hills, L. Inman, Young, An all-glass reference electrode for molten salt systems, J. Sci. Inst., 33 (1956) 438.

[38] K. Dring, R. Dashwood, D. Inman, Predominance diagrams for electrochemical reduction of titanium oxides in molten $\mathrm{CaCl}_{2}$, J. Electrochem. Soc., 152 (2005) D184.

[39] R. Littlewood, Diagrammatic Representation of the Thermodynamics of Metal-Fused Chloride Systems, J. Electrochem. Soc., 109 (1962) 525.

[40] L.D. Brown, R. Abdulaziz, S. Simons, D. Inman, D.J.L. Brett, P.R. Shearing, Predominance diagrams of uranium and plutonum species in both lithium chloride-potassium chloride eutectic and calcium chloride, J. Appl. Electrochem., 43 (2013) 1235. 
[41] I. Barin, Thermodynamical Data of Pure Substances, VCH Verlags Gesellschaft, Weinheim, 1989.

[42] T.R. Wilken, W.R. Morcom, C.A. Wert, J.B. Woodhouse, Reduction of tungsten oxide to tungsten metal, Metall. Trans. B, 7 (1976) 589.

[43] M.W. Chase, NIST-JANAF thermochemical tables, New York, 1998.

[44] Landolt-Bornstein, Thermodynamic Properties of Inorganic Materials, Springer-Verlag, Berlin-Heidelberg, 2001.

[45] M.W. Chase, JANAF thermochemical tables, American Institute of Physics, New York, 1985.

[46] Landolt-Bornstein, Thermodynamic Properties of Inorganic Materials, Springer-Verlag, Berlin-Heidelberg, 1999.

[47] I. Barin, Thermodynamical Data of Pure Substances, VCH Verlags Gesellschaft, Weinheim, 1993.

[48] V. Glushko, Thermocenter of the Russian Academy of Sciences, IVTAN Association, Izhorskaya, 1994.

[49] D.G. Archera, Thermodynamic Properties of the KCI $+\mathrm{H}_{2} \mathrm{O}$ System, J. Phys. Chem. Ref. Data, 28 (1999). 
[50] I. Barin, Thermodynamical Data of Pure Substances, VCH Verlags Gesellschaft, Weinheim, 1995.

[51] B. Jackson, M. Jackson, D. Dye, D. Inman, R. Dashwood, Production of NiTi via the FFC Cambridge process, J. Electrochem. Soc., 155 (2008) E171.

[52] M. Rosenthal, P. Kasten, R. Briggs, Molten-salt reactors — history, status, and potential, Nuclear Technology, 8 (1970) 107.

[53] M.J. Earle, J.M. Esperança, M.A. Gilea, J.N.C. Lopes, L.P. Rebelo, J.W. Magee, K.R. Seddon, J.A. Widegren, The distillation and volatility of ionic liquids, Nature, 439 (2006) 831.

\section{List of Tables and Figures}

Table 1. Gibbs energy of formation at $500{ }^{\circ} \mathrm{C}$ for species in the $\mathrm{Li}-\mathrm{K}-\mathrm{W}-\mathrm{O}-\mathrm{Cl}$ system. 
Fig.1. Schematic of the fluidised cathode process in a molten salt showing various reaction mechanisms between particles in the melt and the electrode. A metal oxide particle could follow route 1 and get fully reduced, or route 1', where it gets partially reduced. These particles could then follow step 2 and deposit on the current collector, or step 2' and bounce off its surface. Partially reduced particles could in turn follow route 3', get fully reduced and, 4', deposit on the current collector, or 3', get fully reduced and, 4', bounce off the current collector back into the molten salt.

Fig. 2. Cross-section of the electrolytic cell used for the reduction of $\mathrm{WO}_{3}$ particles using a fluidised cathode.

Fig. 3. Predominance diagram for the Li-K-W-O-Cl system at $500{ }^{\circ} \mathrm{C}$.

Fig. 4. Cyclic voltammogram of (a) $\mathrm{WO}_{3}$ thin film cathode and (b) $\mathrm{WO}_{3}$ fluidised cathode. In both cases they were performed in $\mathrm{LiCl}-\mathrm{KCl}$ eutectic at $450{ }^{\circ} \mathrm{C}$, scan rate: $50 \mathrm{mV} \mathrm{s}^{-1}$, reference electrode: $\mathrm{Ag} / \mathrm{Ag}^{+}$. 
Fig. 5. Cyclic voltammogram of $\mathrm{WO}_{3}$ fluidised cathode in $\mathrm{LiCl}-\mathrm{KCl}$ eutectic at $450{ }^{\circ} \mathrm{C}$, scan rate: $50 \mathrm{mV} \mathrm{s}^{-1}$, and reference electrode: $\mathrm{Ag} / \mathrm{Ag}^{+}$.

Fig. 6. (a) Chronoamperogram of $\mathrm{WO}_{3}$ fluidised cathode in $\mathrm{LiCl}-\mathrm{KCl}$ eutectic at $450{ }^{\circ} \mathrm{C}, 40 \mathrm{~g}$ $\mathrm{WO}_{3}$, argon flow rate: $800 \mathrm{~cm}^{3} \mathrm{~min}^{-1}$, reference electrode: $\mathrm{Ag} / \mathrm{Ag}^{+}$, set voltage: $-2.14 \mathrm{~V}$; (b) photographs of current collector before reduction process, 1, and after, 2; (c) photograph of the solidified melt showing separate layers of $\mathrm{WO}_{3}$ and $\mathrm{W}$.

Fig. 7. SEM image of the cross-section of the current collector showing the deposited tungsten.

Fig. 8. SEM images of the current collector and the deposit, at different magnitudes, showing homogeneity of reduced particles.

Fig. 9. Chronoamperogram of $\mathrm{WO}_{3}$ fluidised cathode in $\mathrm{LiCl}-\mathrm{KCl}$ eutectic at $450{ }^{\circ} \mathrm{C}, 4 \mathrm{~g}$ $\mathrm{WO}_{3}$, argon flow rate: $800 \mathrm{~cm}^{3} \mathrm{~min}^{-1}$, reference electrode: $\mathrm{Ag} / \mathrm{Ag}^{+}$, set voltage: $-2.135 \mathrm{~V}$.

Fig. 10. Chronoamperograms of $\mathrm{WO}_{3}$ fluidised cathode in $\mathrm{LiCl}-\mathrm{KCl}$ eutectic at $450{ }^{\circ} \mathrm{C}$, argon flow rate: $800 \mathrm{~cm}^{3} \mathrm{~min}^{-1}$, reference electrode: $\mathrm{Ag} / \mathrm{Ag}^{+}$, set voltage: $-2.14 \mathrm{~V}$, for different weight percentages of $\mathrm{WO}_{3}$ in the melt, as indicated. 
Fig. 11. Count of charge per spike relative to a normalised line of best fit, at different $\mathrm{WO}_{3}-$ LiCl-KCl eutectic ratios. Where, (a) is at $0.312 \mathrm{wt} \% \mathrm{WO}_{3}$, (b) $20.00 \mathrm{wt} \%$, and (c) $27.27 \mathrm{wt} \%$.

Fig. 12. Chronoamperogram of $\mathrm{WO}_{3}$ fluidised cathode in LiCl- $\mathrm{KCl}$ eutectic at $450{ }^{\circ} \mathrm{C}, 40 \mathrm{~g}$ $\mathrm{WO}_{3}$, reference electrode: $\mathrm{Ag} / \mathrm{Ag}^{+}$, set voltage: $-2.14 \mathrm{~V}$, showing the effect of different argon flow rates bubbled through the melt.

Fig. 13. Count of charge per spike relative to normalised line of best fit, at different argon flow rates. Where, (a) is at $200 \mathrm{~cm}^{3} \mathrm{~min}^{-1}$, (b) $400 \mathrm{~cm}^{3} \mathrm{~min}^{-1}$, (c) $600 \mathrm{~cm}^{3} \mathrm{~min}^{-1}$, (d) $800 \mathrm{~cm}^{3}$ $\min ^{-1}$, (e) $1000 \mathrm{~cm}^{3} \min ^{-1}$, (f) $1200 \mathrm{~cm}^{3} \min ^{-1}$, (g) $1400 \mathrm{~cm}^{3} \mathrm{~min}^{-1}$, (h) $1600 \mathrm{~cm}^{3} \mathrm{~min}^{-1}$, and (i) $1800 \mathrm{~cm}^{3} \mathrm{~min}^{-1}$. 